\title{
DOI: https://doi.org/10.24297/jssr.v14i0.8142
}

\section{Factors Affecting Physical Activity Participation Among University Students}

\author{
${ }^{1}$ Anatalia Endozo, Ph.D , ${ }^{2}$ Solomon Oluyinka ,Ph.D \\ ${ }^{1}$ Department of Physical Education, Angeles University Foundation, Mc Arthur Highway, Angeles City, \\ ${ }^{2}$ College of Business Administration and Accountancy, Gil Carlos St. Baliuag Bulacan, Philippines \\ endozo.anatalia@auf.edu.ph, solomon467@gmail.com
}

\begin{abstract}
The Physical activities are indispensable to be healthy and away from illness, yet, students ignoring it. The factors affecting physical activity participation among university students in the Philippines examined in this study. Modified International Physical Activity Questionnaire adopted, Stata 13 and SPSS utilized to justify the objectives of study on a 470 samples. Findings revealed that participants who do physical activity for 3 days and accumulating at least 1500 metabolic equivalent tasks (MET) minutes per week or with combination of walking, moderate or vigorous intensity activities accumulating at least 3000 MET minutes were classified as highly active. Other participants were categorized as moderately active and low active/inactive. The results identified that lack of time due to busy lesson schedule was the most significant factors for not participating in physical activity among the samples. Priority on academic success over exercise was the most identified item that hinders individual to participate in physical activities. Thus, recommended the replication of this study to increase the generalizability of achieved results.
\end{abstract}

Keywords: Physical Activity, Factors, Barriers, Obesity, Participation

\section{Introduction}

Physical activity plays an important role in improving and maintaining the health and well-being of every individual. Participation in steady moderate or vigorous physical activity considerably lessens risk for all-cause and cardiovascular-disease mortality. Rogers et al [1] about a third of the world's population doesn't have seems not interested in physical activity, this could be rate of healthiness and economic problems increasing The healthcare sector offers a variety of resources that can promote physical activity programs in primordial, primary, secondary and tertiary institutions [2].

Zwolinsky et al.[3] stated that there is a need to recognize that adoption of active lifestyles programs for adults, introduction of sport physical activity to attract inactive audiences. Warburton et al [4] regular physical activity prevents musculoskeletal disorders such as mechanical low back pain, neck, shoulder pain and, assist to decrease risk of developing coronary heart disease (hypertension, diabetes, osteoporosis, and obesity and colon cancers). Withall et al [5] walking in alone; lack of facilities and appropriate communication strategies hinders people to engage in Physical activity.

In Canada, $85 \%$ of adults and over $90 \%$ of youth do not attain the recommended minimum of 150 minutes of moderate to vigorous physical activity per week [6]. Physical inactivity is responsible for about $6 \%$ of coronary heart disease, a $7 \%$ of type 2 diabetes, a $10 \%$ of breast cancer, and $9 \%$ of the premature birth worldwide, all mentioned can control through physical activities including climbing stairs instead elevators, lifting of things instead of using auto wheels, adopt standing to sitting while waiting $[7,8,9]$.

Saadan et al.[10] barriers to physical activity participation affirmed students entering college heavier weigh than gaining more due to lack of engagement in physical activities, Jensen [11] recommended investigation on factors contributing to why students adding weight during academic sessions. Moreover, related seems limited in the 
context of the Philippines student. Thus, this study aim to analyze current exercise habits and factors affecting physical activity participation among the university students in the Philippines.

\section{Related Literatures}

Advancement in technology and labor-saving devices has afforded people greater ease and convenience at work, school and at home. These have resulted in more free time, which either filled up more work or spend in recreation. All of these, along with personal thoughts and feelings made people resistant to being physically active In order to achieve and maintain a healthy body, regular physical activity are required; it will help to reduce obesity.

Physical activity during and after school hours found significant with academic achievement, cognitive skills and attitudes and classroom behavior. People should be able to overcome obesity through physical activity lifestyle $[12,13,14]$. Pate et al [15] and Waxman [16] agreed that.a regular physical activity of sixty minutes daily improves muscle strength and endurance and reduces the risk of developing chronic, Mcinnis et al [17] about 10 minutes to thirty minutes physical activity is the best predictor for maintaining our weight loss

A survey on prevalence of obesity among adults and youth conducted by Ogden et al [18] number of obese Filipino adults increased by 14.5 percentage points, from 16.6 percent in 1993 to 31.1 percent in 2013. This means that three (3) out of ten (10) Filipino adults are obese, also, among 10 to 19 years old, the prevalence increased by 2.5 points, from 5.8 percent in 2003 to 8.3 percent in 2013 , outcome justified that over nutrition is not common with rich but rampant among the poor [19, 20]; Tudor et al [21] found consistent.

Obesity and an idle lifestyle suggest in Asian countries such as the Philippines, Indonesia, Malaysia and Thailand [22]. Thus, addressing obesity cause by inactivity and other factors is still a big challenge in the Philippines and there is no single factor that causes it. In a summary, the direction and research model of this study demonstrated in the figure 1 of this study.

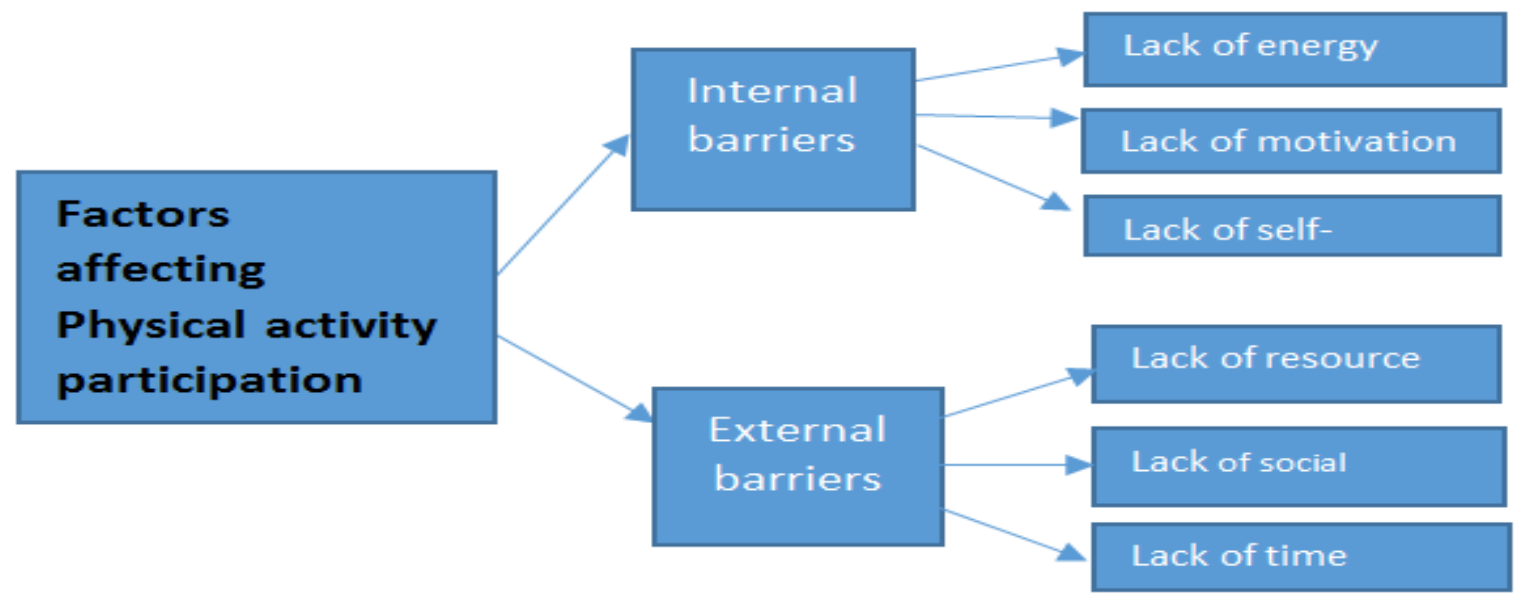

Figure 1: Research Framework of this study

\section{Materials and Research Methods}

\section{Participants and Research Design}

A sample of 470 adopted. There were 222 females (47\%) and 248 males (53 \%) in this study. The samples included many more males than females. Findings revealed that participants involved in physical activity for 3 days achieved accumulation of at least 1500 metabolic equivalent task minutes per week or more days of any combination of walking and intensive exercise accumulating to a 3000 MET minutes /week suggest highly active, below that consider moderately active and low active/inactive. 
Questionnaire by an International Physical Activity Questionnaire by Arzu et al [23] adopted, a 4-point Likert scale [24]. The total sums of the categories' scores were used to calculate total internal and external barriers.

\section{Data Analysis Method}

Values expressed as mean standard error. Statistical significance was determined using a one-way analysis of variance (ANOVA) followed at initial stage, the variances of the physical activity categories noticed not equal, Kruskal-Wallis test considered instead of ANOVA.

Stata 13 and SPSS version utilized as the statistical tools, KMO sampling adequacy of .823 achieved, and alpha equal to .849 achieved. Thus, presents descriptive statistics next.

\section{Results and Discussion}

A total number of thirty respondents did not answer $70 \%$ of the asked questions and excluded from this study. A total of $56.60 \%$ identified to be inactive. It appeared to be no physical activity or some activities were reported but not enough to meet the categories 2 or 3 . Nevertheless, a total good number of $33.19 \%$ were doing 3 more days of vigorous activity of at least 20 minutes per day or 5 or more days of moderate-intensity activity and/or walking of at least 30 minutes per day or of any combination of walking, moderate-intensity or vigorous intensity activities achieving a minimum of at least 600 MET-minutes/week and were identified as moderately active. Overall, a $10.21 \%$ of the respondents were classified as highly active doing vigorous-intensity activity on at least 3 days and accumulating at least $1500 \mathrm{MET}$ minutes/week or with combination of walking, moderate or vigorous intensity activities accumulating at least 3000 MET minutes/week. In the survey, the rate of physical activity participation of males was higher than females.

The World Health Organization reported that, physical inactivity is the fourth leading risk factor for global mortality, causing 6 percent of all death worldwide(high blood pressure, tobacco use, and high blood sugar are the top three risk factors. This 6 percent translates to approximately 3.2 million people deaths annually and 60 percent of the world's population does not meet the recommended amount of physical activity. The United States Department of Health and Human services stated the three main types of physical activity: aerobic, muscle-strengthening and bone-strengthening activities.

The World Health Organization also emphasized that it is important to be scientifically informed about the recommendations outlined by frequency, intensity, type and time (FITT) principle as these recommendations are necessary to produce health benefits. Furthermore, the World Health Organization also endorsed the Global Recommendations on Physical Activity for Health which addresses three age-groups 5-17 y/o, 18-64y/o and $65 \mathrm{y} / \mathrm{o}$ and above. The age groups are classified according to the nature and availability of scientific evidence related to the prevention of non-communicable diseases through physical activity. World Health Organization stated that children and youth should participate in at least 60 minutes of moderate of vigorous physical activity daily in accumulation for the entire day while adults should participate in at least two and half aerobic physical activity throughout the week expected or at least 75 minutes of moderate to vigorous physical activity throughout the week or an equal combination of both.

The enjoyment and social networks offered by physical activity are clearly important motivators from many different groups of people; reasons for participation could be differ among individuals [25]. Conclusively, Lobelo et al [2] broad implementation of physical activity counseling and referral systems suggested has the potential to improve physical activity participation at the population level by complementing and leveraging other efforts.

Also may contribute to achieving global targets for the reduction of inactivity and related morbidity and mortality. Furthermore, factors affecting physical activity participation were presented in the table two of this study. 
Table 1: Description of factors affecting physical activity participation

\begin{tabular}{|c|c|c|c|}
\hline ITEMS: & & ME & \\
\hline Factors affecting physical activity participation & ALL & MALES & FEMALES \\
\hline 1. I've been thinking about exercise is difficult and too tiring & 2.24 & 2.23 & 2.26 \\
\hline 2. I have no energy as much as to be able to do exercise. & 2.2 & 2.12 & 2.09 \\
\hline Lack of energy Score & 4.35 & 4.35 & 4.35 \\
\hline $\begin{array}{l}\text { 3. I've been thinking about other recreational activities with my } \\
\text { friends are more entertaining than exercise. }\end{array}$ & 2.85 & 2.79 & 2.91 \\
\hline $\begin{array}{l}\text { 4. I have not been thinking about exercise has positive effecs on my } \\
\text { health. }\end{array}$ & 1.7 & 1.75 & 1.64 \\
\hline Lack of motivation Score & 4.54 & 4.54 & 4.55 \\
\hline 5.I've been worried about my looks when I exercise. & 1.93 & 1.93 & 1.94 \\
\hline 6. I have not been thinking about my ability to exercise. & 2.08 & 2.14 & 2.02 \\
\hline Lack of Self-confidence Score & 4.01 & 4.06 & 3.95 \\
\hline Sum of Internal factors Score & 12.91 & 12.95 & 12.86 \\
\hline 7. There is no fitness center that I could get into. & 2.06 & 2.03 & 2.08 \\
\hline 8. I have no exercise equipment at home that I use. & 2.51 & 2.34 & 2.69 \\
\hline Lack of Resource Score & 4.56 & 4.37 & 4.77 \\
\hline 9.My family or friends do not encourage me to exercise. & 1.73 & 1.74 & 1.72 \\
\hline 10. My parents give academic success priority over exercise. & 2.35 & 2.25 & 2.47 \\
\hline Lack of Support & 4.09 & 3.99 & 4.19 \\
\hline $\begin{array}{l}\text { 11.I have no leisure time for exercise because of my busy lesson } \\
\text { schedule. }\end{array}$ & 2.84 & 2.74 & 2.95 \\
\hline $\begin{array}{l}\text { 12. I have no leisure time for exercise because of my social and } \\
\text { family responsibilities. }\end{array}$ & 2.35 & 2.23 & 2.49 \\
\hline Lack of Time & 5.2 & 4.98 & 5.44 \\
\hline Sum of External factors Score & 13.84 & 13.34 & 14.41 \\
\hline
\end{tabular}


Table 1 showed the factors to physical activity participation. It can be gleaned on the table that there were differences in the mean factors to physical activity considering the gender. Female respondents have higher rates on almost all questions compare to male respondents. The total score of the external factors was significantly higher than the score of the internal factors. It was identified that lack of time was one of the most important external factor to physical activity participation with the mean of 5.2 while, lack of motivation with the mean of 4.55 was the most important internal factor that somewhat affect the participation of the respondents in doing physical activity.

In a survey conducted by the National Health Surveillance in Singapore, the percentage of Singaporeans who exercise increased from 20 per cent in 2001 to 22.4 per cent in 2007. This study identified three factors to exercise, No time (54.6 per cent), too tired (12.1 per cent) and too lazy (11.6 per cent). This study strongly supported that lack of time and lack of motivation to exercise affect participation in the physical activities. Not having enough time was the most important factor for not participating in physical activity among the respondents [26]. This means that respondents find exercises difficult and too tiring, also by some means they prefer other recreational activities with their friends as they find it more entertaining than exercise. Likewise, they have not fully realized that exercises have positive effects on their health.

Subsequently, they are worried about how they look when they exercise as they lack self-confidence about their ability to exercise. Equally, respondents were also affected by external physical activity factors like lack of resources, lack of support and lack of time in particular. Some external factors includes lack of fitness center or no exercise equipment at home, also they are encourage by friends and family to exercise as parents give academic success priority over exercise. Lastly and most evidently no leisure time for exercise because of the busy lesson schedule and social and family responsibilities. Although most people recognized that there was health benefits associated with the physical activity, this was not the main reason for participation. Other factors such as weight management, enjoyment, social interaction suggest common reasons for people being physically active $[25,26]$.

In addition, two t-tests with equal variances assumption carried out in this study to determine relationship of respondents' profile and factors and rported in the table 2 of this study.

Table 2 shows that the sum of physical activity internal factors was not significantly different among male and female respondents while the physical activity external factors of male is less with female respondents. The total mean score of the factors of males were less than those of the females.

Table 2: Relationship of Respondent's Profile and Factors to Physical Activity Participation

\begin{tabular}{|l|l|l|l|l|l|l|}
\hline Group & Observed & Mean & Std. Err. & Std.Dev. & \multicolumn{2}{|l|}{ 95\% Conf.Interval } \\
\hline Male & 248 & 26.69 & .46 & 5.08 & 25.39 & 27.19 \\
\hline Female & 222 & 27.26 & .47 & 4.90 & 26.33 & 28.19 \\
\hline Combined & 470 & 26.75 & .33 & 5.04 & 26.10 & 27.39 \\
\hline
\end{tabular}

Two-sample $t$ test with equal variances considered significant as one tailed test significant at $10 \%$ level of significant. The diff mean $\mathrm{t}=1.4785 ; \mathrm{Ho}$ : diff $=0$; degrees of freedom $=\mathrm{Ha}$ : diff $<0$; Ha: diff! = 0; Ha: diff $>0$. However, this study reported $\operatorname{Pr}(\mathrm{T}<\mathrm{t})=0.0703 ; \operatorname{Pr}(|\mathrm{T}|>|\mathrm{t}|)=0.1406 ; \operatorname{Pr}(\mathrm{T}>\mathrm{t})=0.9297$. The result implied that male respondents find more resources for fitness like fitness center or gym to do physical activity. 
In addition, male respondents are more inclined to go to fitness center/gym with friends or family member/s and put their time and energy to such activities over academic and other responsibilities. Research showed that one woman in six has exercised regularly since childhood, compared to more than one in three men. Among the 5 female respondents, 3 confirmed never engage which reported twice the male respondents. Fun, enjoyment and social support were reported more often as predictors of participation and non-participation than perceived health benefits.

This study further presents information about the relationship of respondents profile and physical activity in table 3 of this study towards achieving one of the objectives of this study.

Table 3: Relationship of Respondent's Profile and Physical Activity

\begin{tabular}{|l|l|l|l|l|}
\hline Gender & Low & Moderate & High & Total \\
\hline Male & 134 & 90 & 24 & 248 \\
\hline Female & 132 & 66 & 24 & 222 \\
\hline
\end{tabular}

Table3, showed that female respondents physical activity lower than that of the male respondents It was supported with the fact that going to fitness center is more appealing to male and they are more aware of the benefits of exercises like strengthening of the body and mind, enhancement of self-confidence and selfexpression. Also, suggested that male are more indulge into vigorous activities. Contradictory, dance is more appealing to girls than boys. The percentage of respondents that involved in physical activities also anayzed Thus, presents male and female physical activity of the respondents in figure 2 of this study.

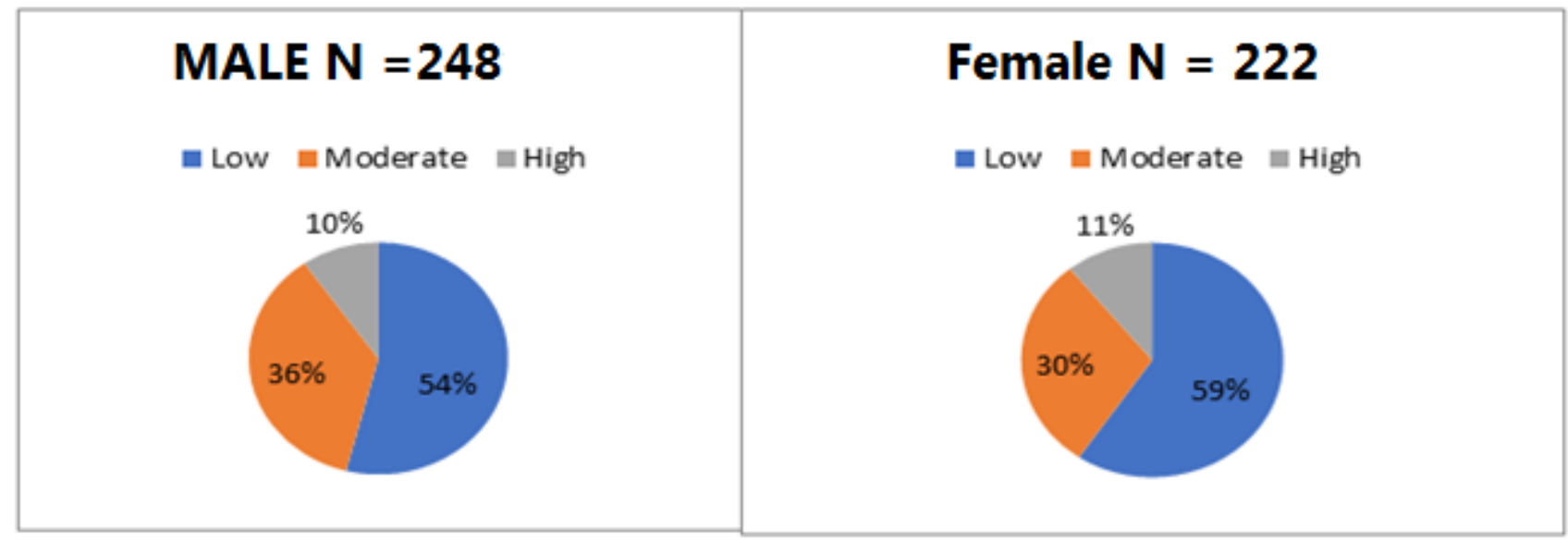

Figure 2: Respondents physical activity percentage details

Figure 2 of this study justified that the males students adopted in this study claimed moderately involved in physical activities with $36 \%$ against $30 \%$, this study also suggested that physical activities at both ends claimed low at female with $59 \%$ and male with $54 \%$. Conclusively, Kendall's tau-b indicated 0.0414 , ASE $=0.063$ of the total sample of 470 respondents to supports the findings of this study.

Azevedo et al [27] regardless of guideline adopted, men were more active than women. Levels of physical activity for men and women expected not to be equal, and variables related to activity levels may not be consistent across the genders, interventions encouraging physical activity ought to take these variations under consideration. Studies argued that aerobic physical activity classes were attended primarily by females [28, 29]. Therefore, it was also expected that female respondents of this study would prefer exercising in a structured settings (both aerobic activity and weight training), more than males [30,31] 
Allender et al [25] qualitative studies towards understanding participation in sport and physical activity among children and adults, the study supported impact of sports, outdoor games, or physical exercise every day on children physical education learning. The study claimed young girls are motivated and engaged in physical activity participation in order to maintain a slim body shape. Adults recognized the significance of sport and physical activity in staving off the effects of aging and providing a social support network.

Finally, most studies identified that lack of confidence, competence, motivation and time as factors affecting physical activity participation [25, 28, 29], Bartlett's test for equality, Kruskal-Wallis equality of-populations rank test, Chi-squared and Probability performed to justify the barriers and current exercise habits of the respondents and reported in table 4 of this study.

Table 4: Barriers and Current Exercise Habits

\begin{tabular}{|l|l|l|l|}
\hline Category & Observed (Obs) & Percent (\%) & Rank Sum \\
\hline Low/Inactive & 266 & $57 \%$ & 16745.00 \\
\hline Moderately Active & 156 & $33 \%$ & 7925.50 \\
\hline Highly Active & 48 & $10 \%$ & 3059.50 \\
\hline
\end{tabular}

Table 4 barriers and current exercise habits reported a Kruskal-Wallis $\mathrm{H}$ test conducted to determine barriers and current exercise habits when categorized in term of inactive $(n=266)$, moderate $(n=156)$ and highly active $(n=48)$ among the respondents. A Kruskal-Wallis $H$ test showed that there was a statistically significant difference in among categorized as the observed $\chi^{2}$-value indicated 6.798 , with degrees of freedom of equal and significance level of 0.0334 , study noticed no tie data among the categorized., so, tie test ignored. There is significant relationship between factors scores among the respondents, their current exercise habit varies considering the preferences, choices, capabilities, abilities and such factors. The responses of the students on the factors to physical activity significantly differed based on how the respondents coped up and dealt with all the factors to participate to physical activity.

Conversely, results of the present study offered insight into conditions beneficial to the development of effective physical activity interventions. Understanding the individual preferences is important; current exercise habits and preferences that are linked to both adherence behaviors and various psychological responses to physical activity $[29,30]$. It has been suggested that physical activity interventions are most beneficial when they are tailored to individual preferences and that a better understanding of these preferences could lead to increased adherence to exercise programs. Thus, beneficial to gain an understanding of some of the personal factors that might influence these individual preferences. One personal factor that is examined in the present study is gender. Reports of physical activity behavior provide support for a suggestion that males and females have different preferences for physical activity contexts.

\section{Conclusions and Recommendation}

This study analyzed habits and factors affecting physical activity participation among university students in the Region III of the Philippines. Firstly, findings of this concluded study revealed that majority of the participants have low level of participation in physical activity. Furthermore, data indicated that male respondents are more physically active than female respondents. Data showed than female's physical activity was lower than those of the males. 
Secondly, it was identified that lack of time was one of the most important external factors to physical activity participation while lack of motivation was the most important internal factor that somewhat affect the participation of the respondents in doing physical activity.

Thirdly, data showed that the sum of physical activity internal factors was not significantly different among male and female respondents while the physical activity external factors of male are less with female respondents. The total mean score of the factors of males were less than those of the females.

Fourthly, overcoming factors is a skill that will help individual to find ways to stay physically active despite various factors [31]. Participation in physical activity among university students is affected by set of factors and that are unique to this population [32]).

Lastly, there is significant relationship between factors scores of the respondents' physical activity participation categories. The respondents' current exercise habit varies considering the preferences, choices, capabilities, abilities and such factors.Moreover, given the results, it is important to assess the current exercise habits and the factors affecting physical activity participation. It is imperative to identify the daily physical activities, time spent in it, and its intensity. A person who knows about physical fitness has an advantage over others and a person who makes concerted effort to adopt an active lifestyle will likely be more productive, with a quality of life that is better than those who are physically inactive [31]. To optimize health, one must be active. Choosing to live healthy requires constant effort by assessing ones current behaviors, be well-informed of the consequences, commit and plan the necessary changes and employ sound techniques to modify these behavior. Physiological, psychological and behavioral factors among others can influence one's plans to become physically active. People should be able to overcome factors affecting physical activity participation to adopt a physically active lifestyle. Getting aware with the various factors to physical activity is essential to creating and designing strategies to overcome them.

Future research should utilize this information to develop intervention strategies that have a greater likelihood of success. In addition, future study should focus on theoretical and evidence base informing policy and health promotion.

\section{Conflicts of Interest}

Authors declared no conflcts of interest

\section{Funding Statement}

Authors decleared personal funding

\section{References}

1. Rogers, L. Q., Carter, S. J., Williams, G., \& Courneya, K. S. (2018). Physical activity. In Handbook of Cancer Survivorship (pp. 287-307). Springer, Cham.

2. Lobelo, F., Stoutenberg, M., \& Hutber, A. (2014). The exercise is medicine global health initiative: a 2014 update. Br J Sports Med, bjsports-2013

3. Zwolinsky, McKenna and Pringle, 2016; How Can the Health System Benefit from Increasing Participation in Sport, Exercise and Physical Activity?. In Sports-Based Health Interventions (pp. 29-52). Springer, New York, NY.

4. Warburton, D. E., Nicol, C. W., \& Bredin, S. S. (2006). Health benefits of physical activity: the evidence. Cmaj, 174(6), 801-809. 
5. Withall, J., Jago, R., \& Fox, K. R. (2011). Why some do but most don't. Barriers and enablers to engaging low-income groups in physical activity programmes: A mixed methods study. BMC public health, 11(1), 507.

6. Bailey, R., Hillman, C., Arent, S., \& Petitpas, A. (2013). Physical activity: An underestimated investment in human capital?. Journal of physical activity and health, 10(3), 289-308.

7. Belanger, M., Sabiston, C. M., Barnett, T. A., O'Loughlin, E., Ward, S., Contreras, G., \& O'Loughlin, J. (2015). Number of years of participation in some, but not all, types of physical activity during adolescence predicts level of physical activity in adulthood: Results from a 13-year study. International Journal of Behavioral Nutrition and Physical Activity, 12(1), 76.

8. Eather, N., Morgan, P. J., \& Lubans, D. R. (2013). Improving the fitness and physical activity levels of primary school children: Results of the Fit-4-Fun group randomized controlled trial. Preventive medicine, 56(1), 12-19.

9. Haskell, W. L., Lee, I. M., Pate, R. R., Powell, K. E., Blair, S. N., Franklin, B. A.,\& Bauman, A. (2007). Physical activity and public health: updated recommendation for adults from the American College of Sports Medicine and the American Heart Association. Circulation, 116(9), 1081.

10. Saadan, R., Jano, Z., Sidek, S., \& Bokhari, M. (2015). Perceived Barriers in Physical Activities among University Students. Journal of Human Capital Development (JHCD), 8(1), 39-46.

11. Jensen, J. A. (2007). Weight stability and influences upon eating and exercise behaviors among college students

12. Donnelly, J. E., \& Lambourne, K. (2011). Classroom-based physical activity, cognition, and academic achievement. Preventive medicine, 52, S36-S42.

13. Rasberry, C. N., Lee, S. M., Robin, L., Laris, B. A., Russell, L. A., Coyle, K. K., \& Nihiser, A. J. (2011). The association between school-based physical activity, including physical education, and academic performance: a systematic review of the literature. Preventive medicine, 52, S10-S20.

14. Thompson, J. L., Jago, R., Brockman, R., Cartwright, K., Page, A. S., \& Fox, K. R. (2010). Physically active families-de-bunking the myth? A qualitative study of family participation in physical activity. Child: care, health and development, 36(2), 265-274.

15. Pate, R. R., Pratt, M., Blair, S. N., Haskell, W. L., Macera, C. A., Bouchard, C., \& Kriska, A. (1995). Physical activity and public health: a recommendation from the Centers for Disease Control and Prevention and the American College of Sports Medicine. Jama, 273(5), 402-407.

16. Waxman, A. (2004). WHO global strategy on diet, physical activity and health. Food and nutrition bulletin, 25(3), 292-302.

17. Mcinnis, K. J., Franklin, B. A., \& Rippe, J. M. (2003). Counseling for physical activity in overweight and obese patients. American family physician, 67(6), 1249-1256.

18. Ogden, C. L., Carroll, M. D., Fryar, C. D., \& Flegal, K. M. (2015). Prevalence of obesity among adults and youth: United States, 2011-2014 (pp. 1-8). Washington, DC: US Department of Health and Human Services, Centers for Disease Control and Prevention, National Center for Health Statistics.

19. Haines, J., Neumark-Sztainer, D., Wall, M., \& Story, M. (2007). Personal, behavioral, and environmental risk and protective factors for adolescent overweight. Obesity, 15(11), 2748-2760. 
20. Dunstan, D. W., Howard, B., Healy, G. N., \& Owen, N. (2012). Too much sitting-a health hazard. Diabetes research and clinical practice, 97(3), 368-376.

21. Tudor-Locke, C., Ainsworth, B. E., Adair, L. S., Du, S., Lee, N., \& Popkin, B. M. (2007). Cross-sectional comparison of physical activity and inactivity patterns in Chinese and Filipino youth. Child: care, health and development, 33(1), 59-66.

22. Khor, G. L. (2008). Food-based approaches to combat the double burden among the poor: challenges in the Asian context. Asia Pacific journal of clinical nutrition, 17(S1), 111-115.

23. Arzu, D., Tuzun, E. H., \& Eker, L. (2006). Perceived barriers to physical activity in university students. Journal of sports science \& medicine, 5(4), 615.

24. Hartley, S. L., \& MacLean Jr, W. E. (2006). A review of the reliability and validity of Likert-type scales for people with intellectual disability. Journal of Intellectual Disability Research, 50(11), 813-827.

25. Allender, S., Cowburn, G., \& Foster, C. (2006), Understanding participation in sport and physical activity among children and adults: a review of qualitative studies. Health education research, 21(6), 826-835.

26. Lim, W. Y., Ma, S., Heng, D., Bhalla, V., \& Chew, S. K. (2007). Gender, ethnicity, health behaviour \& selfrated health in Singapore. BMC Public Health, 7(1), 184.

27. Azevedo, M. R., Araújo, C. L. P., Reichert, F. F., Siqueira, F. V., da Silva, M. C., \& Hallal, P. C. (2007). Gender differences in leisure-time physical activity. International journal of public health, 52(1), 8.

28. Barr-Anderson, D. J., Adams-Wynn, A. W., DiSantis, K. I., \& Kumanyika, S. (2013). Family-focused physical activity, diet and obesity interventions in A frican-A merican girls: a systematic review. Obesity Reviews, 14(1), 29-51.

29. Ryan, A. S., Ge, S., Blumenthal, J. B., Serra, M. C., Prior, S. J., \& Goldberg, A. P. (2014). Aerobic exercise and weight loss reduce vascular markers of inflammation and improve insulin sensitivity in obese women. Journal of the American Geriatrics Society, 62(4), 607-614

30. Chomitz, V. R., Slining, M. M., McGowan, R. J., Mitchell, S. E., Dawson, G. F., \& Hacker, K. A. (2009). Is there a relationship between physical fitness and academic achievement? Positive results from public school children in the Northeastern United States. Journal of School Health, 79(1), 30-37..

31. Hallal, P. C., Andersen, L. B., Bull, F. C., Guthold, R., Haskell, W., Ekelund, U., \& Lancet Physical Activity Series Working Group. (2012). Global physical activity levels: surveillance progress, pitfalls, and prospects. The lancet, 380(9838), 247-257.

32. Rimmer, J. H., Riley, B., Wang, E., Rauworth, A., \& Jurkowski, J. (2004). Physical activity participation among persons with disabilities: barriers and facilitators. American journal of preventive medicine, 26(5), 419-425 